\title{
A Design of Learning Management System for Electronic Secretary Based on Ubiquitous Learning
}

\author{
Guangran Liu \\ School of Information Technology Engineering \\ Tianjin University of Technology and Education (TUTE) \\ Tianjin, China \\ liuguangran@163.com
}

Bencai Gao

School of Information Technology Engineering

Tianjin University of Technology and Education

Tianjin, China

gao.zh.m0159@gmail.com
Jun Lou

Tianjin Hepu Science and Technology Co., Ltd.

Tianjin, China

lj@course-book.com

\begin{abstract}
The proposed ubiquitous computing creates a new calculation model. Ubiquitous learning based on ubiquitous computing is the trend of current study theory. This paper introduces the concept of ubiquitous learning, analyzes and summarizes its thoughts and main characteristics, constructs the model of a ubiquitous learning environment. With the guidance of constructed ubiquitous learning environment model, we design the management system for electronic course-lattice, and use the metaphor of secretary naming the management system as electronic secretary.
\end{abstract}

Index Terms-ubiquitous learning; course-lattice; ubiquitous computing; management system

\section{INTRODUCTION}

\section{A. The Concept of Ubiquitous Learning}

Except ubiquitous learning, there are life-long learning, e-learning, mobile learning and some distance education post-modernist ideas. The progressive relationship exists between the former and the latter, and the former is more scientific and efficient than the latter. The origins of ubiquitous learning is dated to 1988 , when
Mark • Wither (1952-1999) introduced the "Ubiquitous Computing” concept. It was pointed out that the most sophisticated technology is the technology that disappears, that is, with the ubiquitous technology and network for the center, the physical space intelligent and all things networking were made. That is to embed the computer into physical space, and to make it networking. In this way, it makes information so smoothly between the physical environment and things as in electronic space, as if people live in it [1].

Ubiquitous learning is supported by ubiquitous computing technology. The most important application of ubiquitous computing in the human study is to build a ubiquitous learning platform and environment for learning. Of course, not only a single peripheral support role, which does play in the building process of an ubiquitous learning environment, but also a cognitive tool, a learning partner, a directly learning objectives [2]. 


\section{B. The Ideological and Characteristics of Ubiquitous}

\section{Learning}

Ubiquitous learning is a human-centered and its focus is the studies task itself, the main ideas and features of which were as follows: [3][4][5][7]

- Ubiquitous learning environment should have the context of aware features, which means automatically sense the location of learners, the information of environment, ongoing learning activities, and interaction information between learners with the environment and others. It analyzes and processes, and then understands the learners' needs and behaviors. According to that, we can provide the highest performance environment [6].

- Ubiquitous learning pays full attention to individual needs, preferences, learning styles and learning experience of learners in learning. Learners were allowed to learn in a natural environment by a natural way. Natural environment is living environment of learners, which include the physical environment and social environment.

- Ubiquitous learning focuses on the setting of the real problem. Learners can learn by finding and building the necessary knowledge points to solve problems. Learners are the problem-solver and the significant constructor. Ubiquitous learning can make learners develop problem-solving skills and advanced thinking ability.

- Ubiquitous learning intends to break the learning from theory to theory of closed-type small cycles, fully reflects the interaction and influence between learners and social environment, and promotes the learning from the "artificial" to "ecological regression."

- Ubiquitous learning focuses on the development of evaluation which regards the main body as the orientations. It also advocates the value of diversity and respects differences because value diversity and difference do exist, knowledge among the main knowledge bodies will be unevenly distributed, and then result in knowledge flows.
- What Ubiquitous learning concerns is not the state of knowledge, but the activities people participated in, the tools' nature they use in the activities, social relations and the relationship between contexts of the partners in the activities, purpose or intent and events or results object of the activities[15].

\section{The Model of Ubiquitous Learning Environment and} its Inspiration for the DevelopedLearning

Management System

Ubiquitous learning environment is a dynamic circulatory system, and it is not closed, but an open ecosystem. The ultimate goal of learner's awareness can be captured and analyzed by the surrounding environment, and the real problem for learning can be formed through intelligence services. Ubiquitous learning environment in the territory of pulse sensing technology is based on perception of technology which is intravenous dynamic changes of the environment, to achieve a variety of intelligence services. Ubiquitous learning environment model as shown [11][12][13][14]:

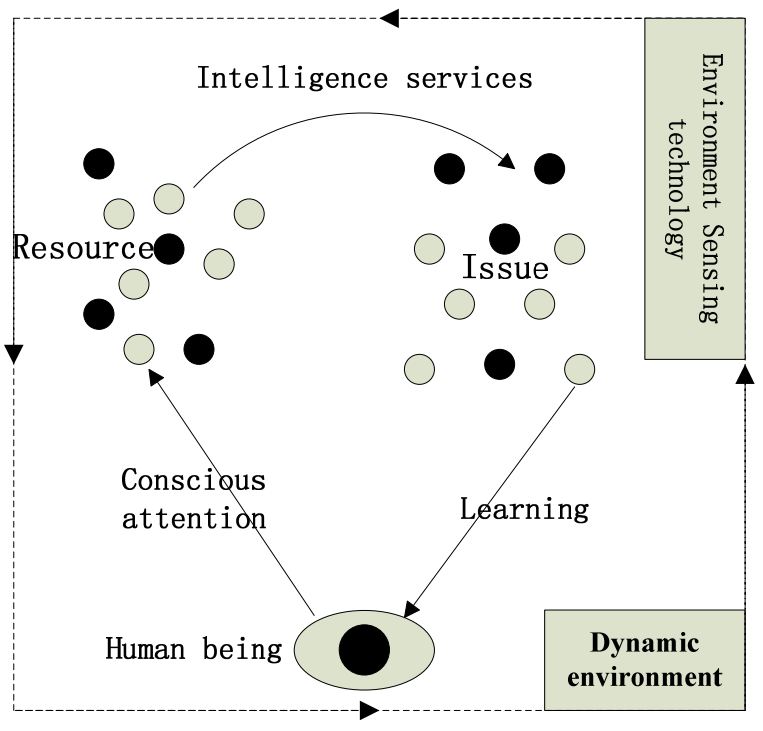

Figure1. the model of Ubiquitous learning environment

- In view of the ubiquitous learning environment model, the learning management system should be as intelligent as possible, so that the time and energy learners put into the learning of operating system function can be as little as possible.

- Learning management system should be able to record and analyze each learner's study habits, 
and summarize the users' individual learning preferences and learning style effectively.

- Learning management system should be able to respect individual differences, promote a wide range of individual needs, and provide the different learning management services.

- Learning management system should give full play to the learner's consciousness of innovation and encourage the students to independently build their own curriculum system.

- Learning management system should provide the conditions for free communication of students, including the communication between teachers and students, so that learners can master the learning dynamic timely, adjust their learning strategies constantly to improve learning outcomes.

- Learning management system should be able to provide learners' timely and effective help in order to avoid the system users frustrated and protect the enthusiasm of learners then improve learning efficiency.

- Learning management system should provide real exchange learning opportunities for learners in the widest range, such as online multiplayer and video chat.

\section{The metaphor of electronic secretary}

In real life, a secretary is the assistant to help us prepare material, arrange time, and provide service. They help us resolve a lot of unnecessary troubles, and save us a lot of time and energy so our work will be easy and efficient. An electronic secretary learning management system can help students manage course notes, without fear of loss. The notes are recorded regardless of any place in the course, and it will be bound together with the content and index. It also has a collection of personalized classified and personalized program version management. The guiding ideology of electronic secretary learning management system exactly coincides with the secretary's functions, so we call the learning management system as e-secretary learning management system.

The course management system based on ubiquitous learning requires solving practical problems in the work and life in time, which takes learners as center and focuses on the learning task. As a result, the course management system can be called "electronic secretary ".

\section{THE DESIGN OF LEARNING MANAGEMENT SYSTEM FOR ELECTRONIC ELECTRONIC SECRETARY}

\section{A. The Design of System Overall Architecture}

The C / S mode is used in the system, and is also used in the structured design techniques. Management system architecture is shown in figure 1 :

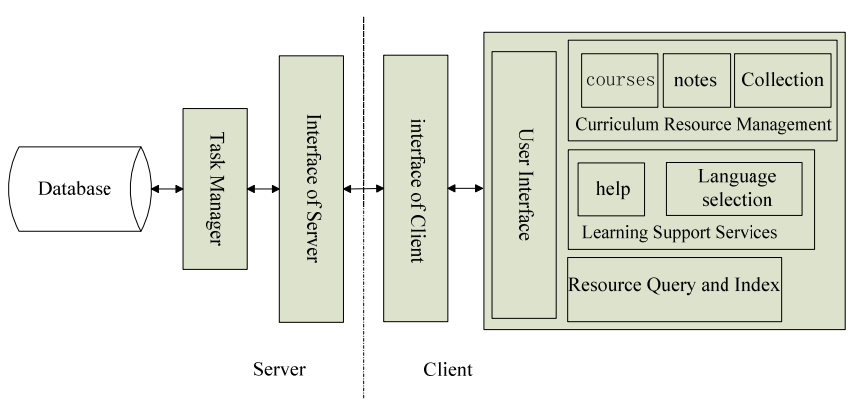

Figure2. the system architecture

Users need to download and install the client program, and use e-mail certification to register and login system. After logging into the system, users access the curriculum, notes, collections for curriculum resource management and learning. Users can also choose learning support services such as help and changing different languages. System also offers instant messaging display window, resource queries and index functions.

\section{B. The Design of System Structure}

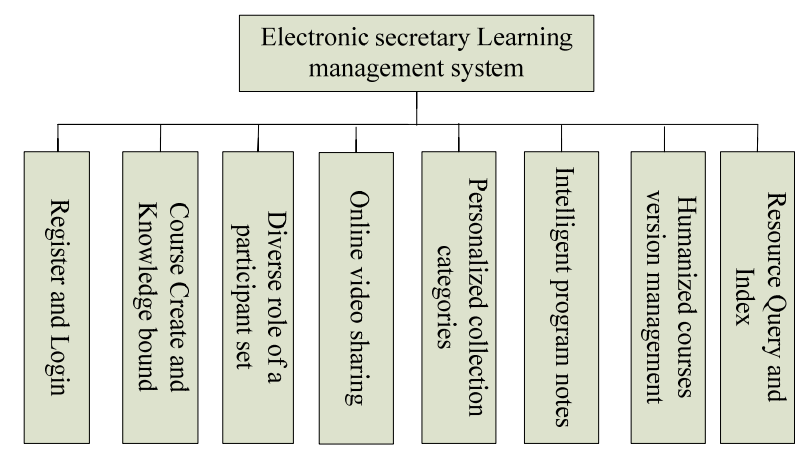

Figure3. the system structure

Besides the basic learning management features, this system also supports multiplayer online video sharing, collection of personalized classified, intelligence programs notes, personalized program version management. Details are as follows: [8] 
- The system uses P2P technology and supports multiplayer online video sharing, low-latency, secure and reliable, and needn't install plug-ins. So that learners will be able to break latching small cycles from learning theory to learning theory, fully reflects the interaction and influence between learning and social environment to promote learning from the "artificial" to "ecological regression".

- The learners who use the system learning course can write the study notes and needn't worry about losing them. The course notes wherever recorded and the course content will be bound together and indexed. This learner will be able to locate in the intelligent environment and avoid the learners to increase the cognitive load, because of technical problems.
- You can always collect courses and knowledge points, just points, clicks, collections, while supporting personal collection of classification. All of this makes the course more suitable for learners achieve personalize learning, and it is conducive to train innovative awareness and creative ability of learners.

- The same course, for different types of students, different depths and different needs of the semester, can be set up in different versions, and choose to display the corresponding version. Accordingly to above, we can provide the highest performance learning environment.

\section{The Design of System Business Processes}

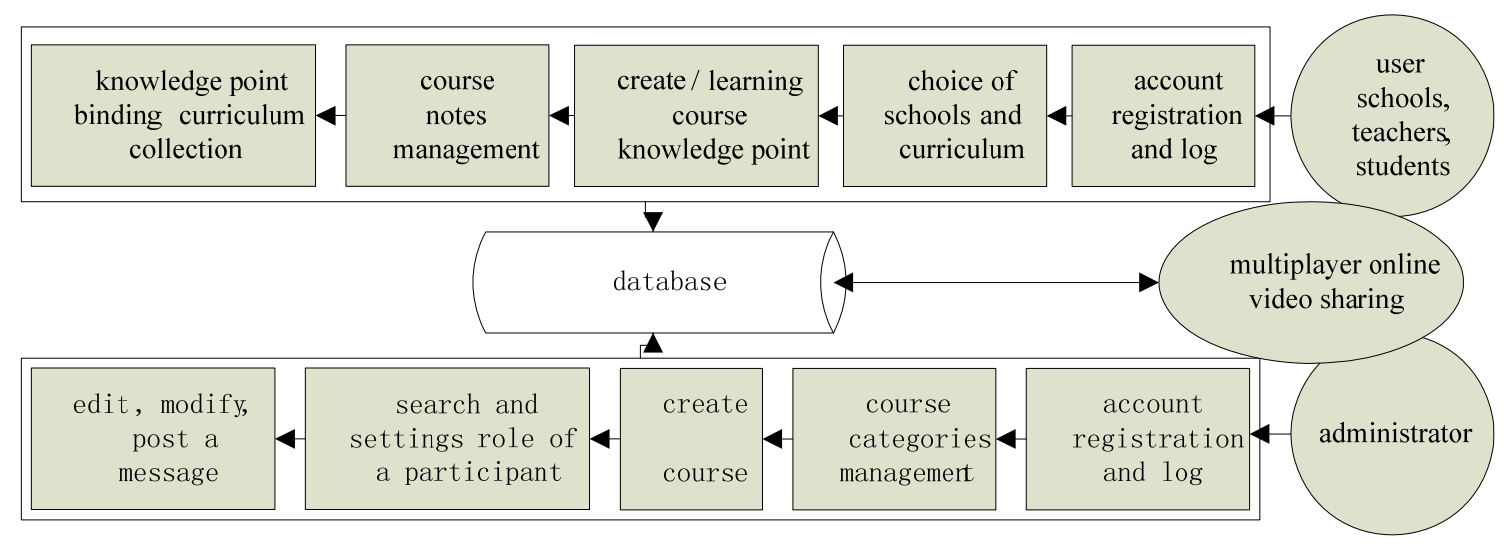

Figure4. the business processes

Figure 4 shows the business process of electronic secretary management system, which is divided into two main lines because of different roles:

- Role 1: Users include schools, teachers and students, whom all login into the system through the registration verification. First of all the participants choose schools and courses and record the appropriate course notes in the process of course learning. After having learned knowledge points, learners can organize and bind them to form a course which suits to their characteristics and collects it.

- Role 2: The platform administrators and school administrators need to verify the user's identity to log into the system. They can create courses and classified management; add the course of attribute information, use query the indexing functions, and set roles of the course participants. And administrators have the right to edit, modify and distribute various instant messaging related to courses.

\section{The Design of System Database}




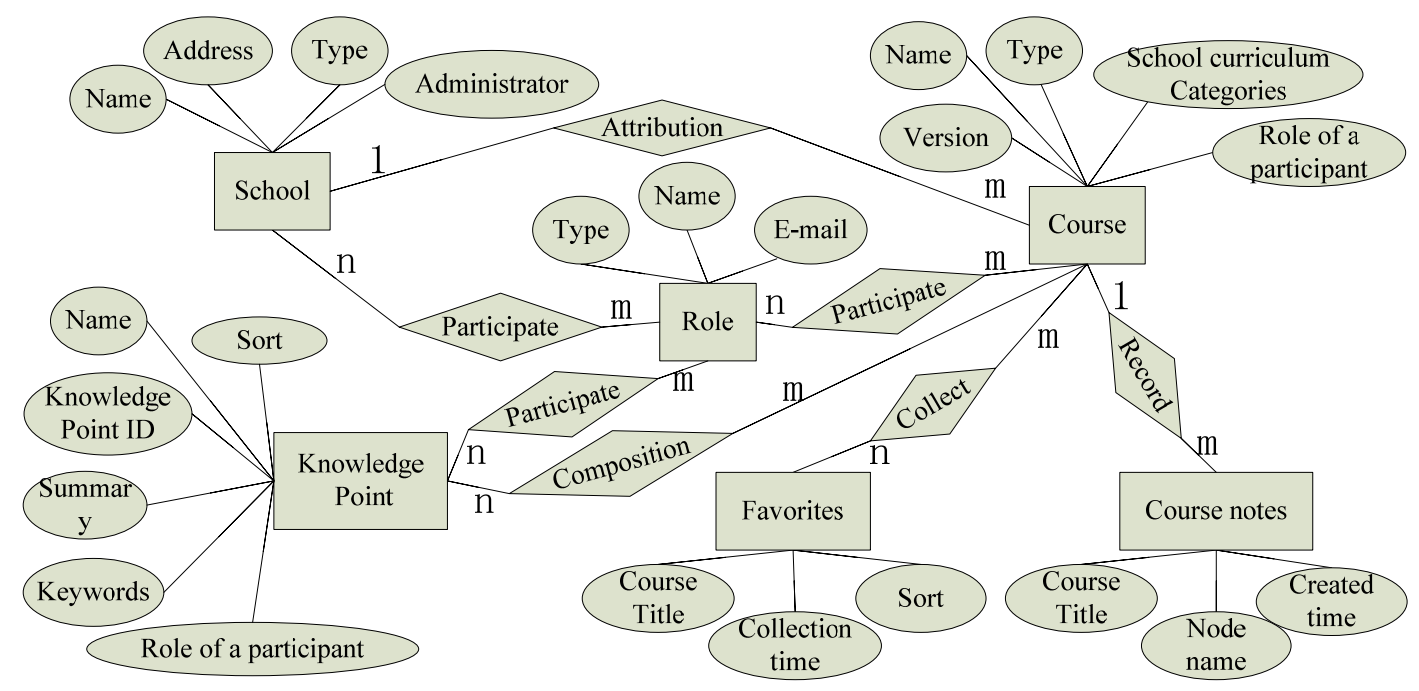

Figure 5. the basic E-R diagram

The focus of the entire system is data modeling. By using SqlServer2000 to create the database and the name of database is c-lattice. As the figure 3 shows, the database has six basic tables and they are the school information table, curriculum table, knowledge points table, the information of role table, curriculum collection table and notes table.

\section{E. The Design of User Interface}

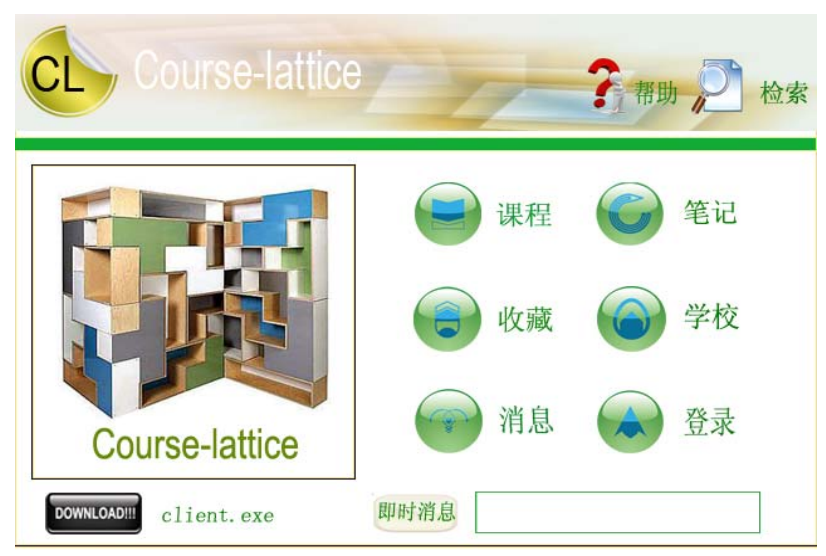

Figure6. the design of user interface

The user interface of the system includes a main function links: including courses, notes, collections, schools, news, logging and accessibility links, searching and additionally. There are client download link and instant messaging display window.

\section{F. The Designt of Systerm Main Functions Modules}

According to the preceding analyses, the main function modules of this system can be divided into course management module, knowledge point management module, notes management module and collection management module. And the four modules are programmed separately.

- The course module is mainly to manage new course information, including course catalogs management, course metadata information management, role information management and course description information management. Teachers can set up courses by searching knowledge points and the roles information of knowledge points requires to be stated.

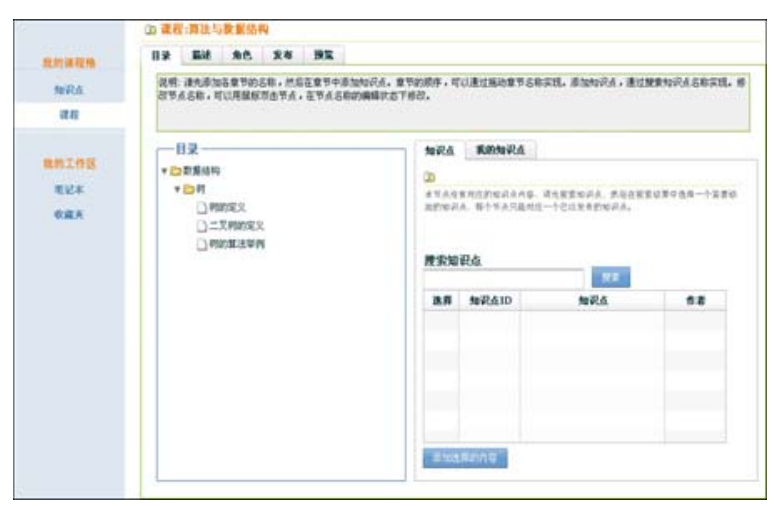

Figure7. the design of course module 
- Knowledge point module is independent of the course module and knowledge point. Id is the unique identification of the search and query. Metadata information must be filled when a knowledge point is created. A knowledge point can include text files, flash files, video files and the expand links.

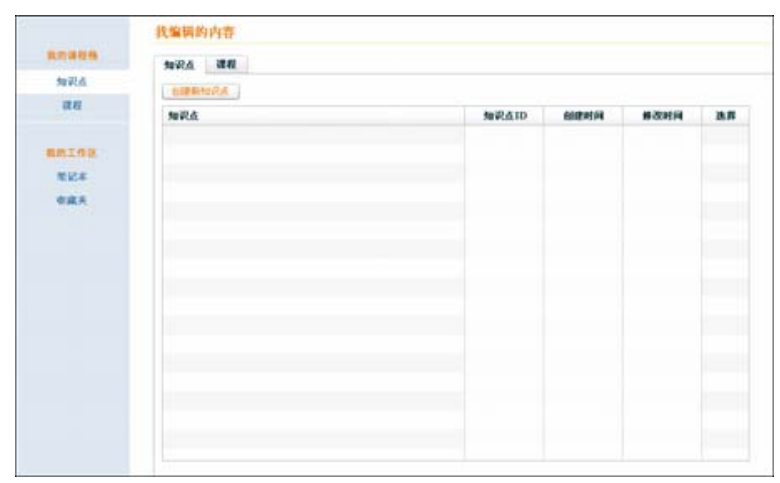

Figure8. the design of knowledge point module

- Note that modules are used for the process of course learning. Course notes are recorded in the form of text under the corresponding directory of the courses and knowledge points. We can upload server to save in order to prevent from losing.

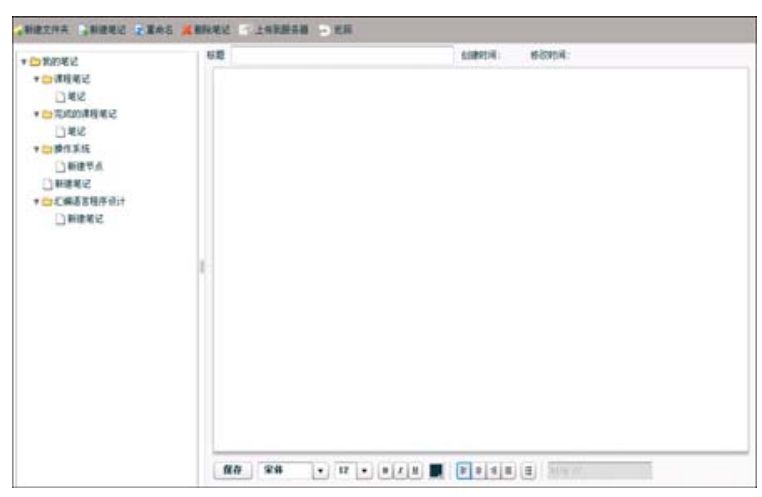

Figure9. the design of note module

- A collection module is used to collect courses. For the knowledge points which the learner interest in and need to further study, Users can create different classified collections and the collections within different categories can move freely.

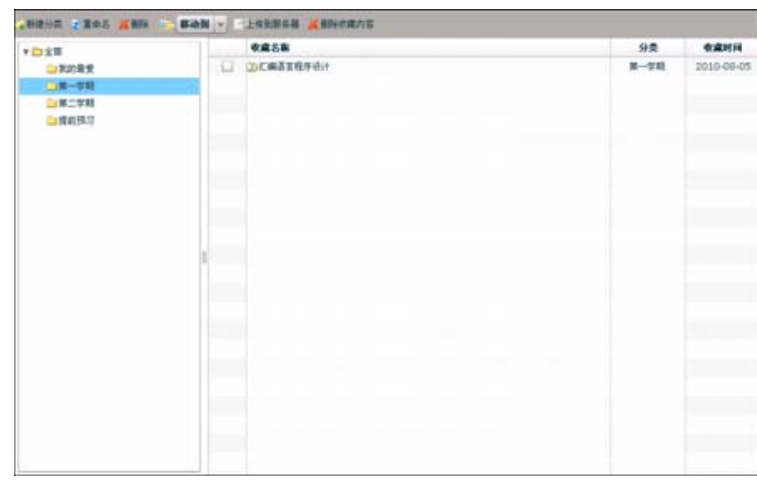

Figure10. the design of collection module

\section{THE DEVELOPMENT ENVIRONMENT OF LEARNING MANAGEMENT SYSTEM FOR ELECTRONIC ELECTRONIC SECRETARY}

This online learning environment system is based on the $\mathrm{C} / \mathrm{S}$ structure and the development environment architecture of the system is Drupal . Drupal is an open source content management system (CMS) based on PHP and includes a variety of functional modules ,such as user management, module management, content indexing and search, blog, forum and so on.

Drupal architecture has some important core ideas, which makes it different from other content management system, with more distinct characteristics, its core ideas include [9] [10]:

\begin{tabular}{|c|c|}
\hline $\mathrm{co}$ & $\begin{array}{l}\text { Drupal development supports open, } \\
\text { collaborative work systems and methods }\end{array}$ \\
\hline \multicolumn{2}{|c|}{----------} \\
\hline Standards & $\begin{array}{l}\text { Drupal support existing and new } \\
\text { promulgated standards }\end{array}$ \\
\hline \multicolumn{2}{|c|}{-----------} \\
\hline Open so & $\begin{array}{c}\text { Drupal is Open source system based on the } \\
\text { development of Free software, and it also } \\
\text { support open source database system }\end{array}$ \\
\hline \multicolumn{2}{|c|}{-----------1} \\
\hline Quality coding & $\begin{array}{c}\text { Drupal using high-quality, structured } \\
\text { code, much better than the general } \\
\text { development of functional }\end{array}$ \\
\hline \multicolumn{2}{|c|}{----------- development of functional } \\
\hline Easy of & $\begin{array}{l}\text { Drupal have a high ease of use for } \\
\text { developers, managers, and users }\end{array}$ \\
\hline \multicolumn{2}{|c|}{----------} \\
\hline $\begin{array}{l}\text { Modular and } \\
\text { extensible }\end{array}$ & $\begin{array}{c}\text { Drupal provides a simple but powerful } \\
\text { kernel. }\end{array}$ \\
\hline \multicolumn{2}{|c|}{----------} \\
\hline $\begin{array}{r}\text { Low } r \\
\text { dem }\end{array}$ & $\begin{array}{l}\text { Drupal } P \\
\text { the ef }\end{array}$ \\
\hline
\end{tabular}

Figure11. The core ideas of Drupal architecture 


\section{CONCLUSION}

Ubiquitous computing will be an important direction for the development of information technology in the future. Its related technology will help to realize ubiquitous computing model and to improve it further. Ubiquitous computing will inject new vitality into information education, ubiquitous computing applications in education will become a new hotspot. Based on ubiquitous learning ideas, this article designed the electronic secretary learning management system. There is a great gap between the present state and the full realization of ubiquitous learning, so the research needs to continue.

\section{REFERENCES}

[1] Mark Weiser. Hot Topic: Ubiquitous Computing [J].IEEE Computer, 1993,(10):71-72.

[2] Hwang, G. J., Yang, T. C., Tsai, C.C. \& Yang, S. J. H. (2009). A context-aware ubiquitous learning environment for conducting complex science experiments. Computers \& Education, 53(2), 402-413.

[3] Chen, Y.S., Kao, T.C., Sheu, J.P. and Chiang, C.Y.(2002).A Mobile Scaffolding-A id-Based Bird-Watching Learning System. In M. Milrad, H. U. Hoppe and Kinshuk(Eds.), IEEE International Workshop on $\mathrm{W}$ ireless and Mobile Technologies in Education(pp.15-22).Los Alamitos, USA:IEEE Computer Society.

[4] Soo-Hwan Kim, HyeonCheol Kim. Jin-Tae Lee, Seon-Kwan Han. Chul-Hyun Lee(2008). A design of u-Learning system based on memory theories in ubiquitous environments. Wseas Transactions on Advance in Engineering Education 2008, Volume 5(pp.77-82).

[5] Reeves, T.C., Herrington, J., \& O liver, R. (2002).Authentic activities and online learning. In A. Goody, J. Herrington, \& M. North cote (Eds.), Quality conversations: Research and Development in Higher Education, Volume 25 (pp.562-567).

[6] Liu, G. Z. \& Hwang, G. J. (2009). A key step to understanding paradigm shifts in e-learning: Towards context-aware ubiquitous learning. British Journal of Educational Technology, 40(6), doi: 10.1111/j.1467-8535.2009.00976.x

[7] Jones, V. \& Jo, J.H. (2004). Ubiquitous learning environment: An adaptive teaching system using ubiquitous technology. In R. Atkinson, C. McBeath, D. Jonas-Dwyer \& R. Phillips (Eds), Beyond the comfort zone: Proceedings of the 21st ASCILITE Conference (pp. 468-474).

[8] CBAIR.air : http://www.hepu.com.cn/

[9] http : || www. drupalsites. net/ [ EB] . 2006-07-23.

[10] http : || top. drupalsites. net/ [ EB] . 2006-07-23.
[11] A.K.Dey,A.Understanding and Using Context[J]. Journal of Personal and Ubiquitous Computing,2001,5(1):4-7.

[12] Friedemann Mattern.Ubiquitous Computing:From smart Devices to smart every Dey objects[J]. Information Appliances, 2000,(3):6-12.

[13] Koper, E. J. R. , \& Sloep, P. ( 2003) . Learning networks: connecting peop le, organizations, autonomous agents and learning resources to establish the emergence of effective lifelong learning (OTECRTD Programme Plan 2003-2008 ) [M]. Heerlen: Open University ofthe Netherlands.

[14] Wagner, A. (2000) . Tertiary education and lifelong learning: perspectives, findings and issues from OECD work [J]. Higher Education Management, 11 (1) : 55256.

[15] Daniel, J. S. (1996 ) . Mega2universities and knowledgemedia: Technology strategies for higher education [M]. London: Kogan Page.

[16] Johan Plomp, Petteri Alahuhta. A Platform for Ubiquitous ContextSensitive Applications [DB/OL].www.inf.ethj.ch/vs/ events/HUK2kW/AlahuhtaPlomp.pdf.

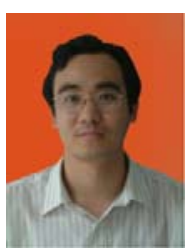

Guangran Liu received the B.S. degree in computer science from Tianjin Normal University,Tianjin, China, in 1990, and the M.S. degree in education technology from Tianjin Normal University,Tianjin, China,in 1993.

He is a professor at the Tianjin University of Techenology and education, Tianjin, china, His main research interests are software engineering of education and digital media technology.

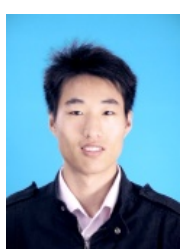

Bencai Gao received the B.S. degree in education technology from Linyi University, Linyi, China, in 2008, and the M.S.degree in education technology from Tianjin University of Techenology and education, Tianjin, China,in 2011.

His current research interests include software engineering of education, ubiquious learning and virtual reality technology.

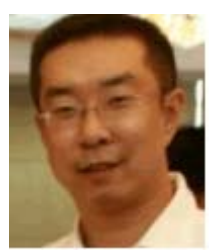

Jun Lou is the Manager of Tianjin Hepu Science and Technology Co., Ltd. Tianjin, China. 